\title{
COVID-19 testing in a UK dental practice - results of a pilot study
}

\author{
Linda Greenwall, ${ }^{\star 1}$ Marcus Cebula, ${ }^{2}$ Joseph Greenwall Cohen ${ }^{1}$ and Susanne Effenberger ${ }^{2}$
}

\section{Key points}

COVID-19 testing protocols should be implemented in UK dental practices for the safety of their teams and patients.
Quick and accurate diagnostics are important to react appropriately without compromising the integrity of the whole dental practice.
Dental practices need to be well informed and adaptable to cope with the changing and dynamic environment.

\begin{abstract}
Objective In December 2019, a novel coronavirus (SARS-CoV-2) caused a disease outbreak that soon became a global pandemic. Dentists are potentially exposed to infectious microorganisms, including SARS-CoV-2, by virtue of the transmission routes and work environment. This study aims to determine the infection load in a dental healthcare setting during the onset of the pandemic in the UK, as well as to evaluate the effectiveness of recommended test regimens in order to estimate potential risks for caregivers and patients in a dynamically changing pandemic environment.
\end{abstract}

Methods Twenty-four persons (dental personnel of one dental office and family contacts) were included in this pilot study, and their infection load was determined between March and May 2020 using antigen and antibody tests.

Results Of the 24 subjects, three tested positive for SARS-CoV-2 and were quarantined accordingly. After six weeks, they tested negative for the virus, had built antibodies and had no remaining symptoms, enabling an efficient return to work.

Conclusion This paper outlines the results of COVID-19 testing in a dental practice during the onset of the pandemic, and discusses possible strategies and protocols to gain certainty in the dental practice, assessing possible testing scenarios that can be performed in a primary healthcare setting.

\section{Introduction}

In December 2019, a novel coronavirus (SARS-CoV-2) caused a new disease outbreak (COVID-19) that became a global pandemic. It is rapidly transmitted through the respiratory tract and can induce pneumonia as well as a number of severe symptoms. ${ }^{1,2}$ As of August 2020, more than 18 million people worldwide have been tested positive for SARS-CoV-2 with more than 700,000 confirmed deaths, resulting in a lockdown of many countries in a bid to stop the virus from continuing to spread and to mitigate the impact on society.

${ }^{1}$ Private Practice, Greenwall Dental, 5 Elm Terrace, NW3 2LL, London, UK; ${ }^{2}$ Clinical Research, DMG Dental-Material Gesellschaft mbH, Elbgaustrasse 248, 22547 Hamburg, Germany.

*Correspondence to: Linda Greenwall

Email address: linda.greenwall@hampsteadhealthcare.org.uk

Refereed Paper.

Accepted 8 March 2021

https://doi.org/10.1038/s41415-021-2849-7
Dentists are potentially exposed to harmful biological factors, including infectious microorganisms, through aerosol generating procedures, contact with blood, infected equipment and patients. ${ }^{1}$ Thus, it became clear that dentistry had to be restricted during the outbreak, which was enforced in March 2020 in the UK when the Office of the Chief Dental Officer advised dentists to restrict their practice to emergencies only. ${ }^{1,3,4,5}$ Dental practices opened again in June 2020 with new protocols and protective measures, screening protocols and triaging to assess patients' COVID-19 status if active disease could not be confirmed. ${ }^{6,7,8,9,10}$

Antigen and antibody tests are available to test for different stages of the disease (Fig. 1). ${ }^{11,12}$ The antigen tests measure the presence of COVID19 RNA in blood, saliva and sputum using polymerase chain reaction (PCR). However, the samples have to be sent to laboratories for processing, which causes some delay. The turnaround can be as quick as 24 hours, but also may be further delayed; for example, due to shipping, in case of remote areas or in times when the capacity of laboratories is stretched. While this delay may not seem long, an infected dentist, for example, may spread the virus to a broad variety of patients over a working day or two. An earlier diagnosis would mean infected individuals can be isolated sooner instead, preventing spreading of the virus to others. In addition, antibody tests to detect immune markers in blood samples are available in many forms. They may validate past infections and indicate some immunity. ${ }^{13}$ SureScreen Diagnostics, for example, have developed a rapid lateral flow diffusion test that only requires $10 \mu \mathrm{l}$ of blood to measure presence of IgG and IgM..$^{14,15,16}$ Both the antigen and the antibody tests are important and, as of August 2020, over 12 million people have been tested in the UK with a testing capacity of over 300,000 per day. ${ }^{17}$

Trying to understand the pandemic is key for dental teams, as is the need to put strategies and protocols in place for treating patients and protecting healthcare workers 
while vaccination programmes are being developed. ${ }^{18,19}$ Testing is essential to gain information and to help control the spread of the virus. ${ }^{20,21}$ This study outlines the results of COVID-19 testing in a UK dental practice during the onset of the pandemic and discusses possible strategies to gain certainty in the dental office, looking for possible testing strategies that can be performed in a primary healthcare setting.

\section{Materials and methods}

Nasopharyngeal swabs were taken from 24 subjects, including members of a dental team who worked in the same dental practice and their immediate family contacts. All subjects consented and symptoms were documented. The tests were taken on members of the dental team or on family contacts of healthcare workers displaying possible symptoms. Further tests were undertaken on healthcare workers that had flu-like symptoms. Five of the swabs were taken at the dental practice on dental team members. The other 19 swabs were taken self-administered following instruction, provided through videos and written directions. Three of the self-testers were insecure in self-administering the nasal swab and were given additional video calls to complete the swab-taking effectively. The age range of the subjects was $17-70$ with a mean age of 38 (SD 14). The collected test samples were sent to Micropathology Ltd laboratory for PCR testing for SARS-CoV-2. Results were received within two days via secure email and subjects were informed immediately. In addition, 14/24 test subjects conducted rapid finger prick (SureScreen Diagnostics) tests to assess whether they had potential immunity and three subjects were subsequently tested using an antibody blood test (Abbott). These 14 subjects were patient-facing personnel and needed urgent testing to ensure a timely and safe return to work.

\section{Results}

Three out of 24 tests were SARS-CoV-2positive (Appendix 1; 9, 12 and 15). Two of the three positive subjects were dental healthcare workers (9 and 12) and one a family contact (15). Subjects 12 and 15 initially had no symptoms, but developed mild COVID-19associated symptoms two days later. Subject 15 was tested at her own home in isolation at the request of the family after showing symptoms.

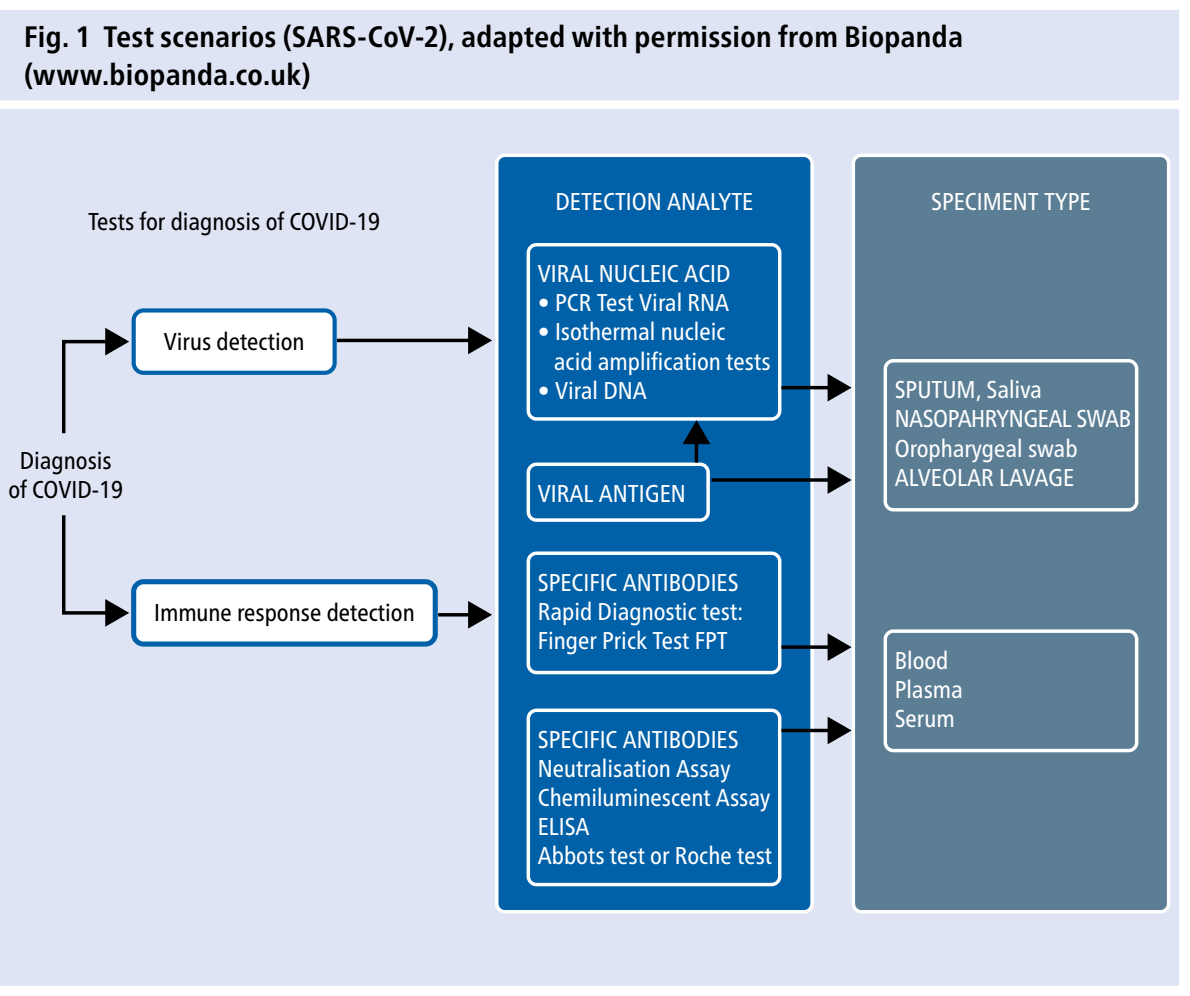

One month later, subjects 9 and 15 , and a nurse (13) who previously tested negative but had possible contact with a COVID-19-positive person at a later date, were tested a second time. Both COVID-19-positive healthcare workers were tested positive a second time, whereas the nurse (13) tested negative. Two weeks later, the two COVID-19-positive subjects were tested yet again, receiving a negative result.

Many of the healthcare workers had flu-like symptoms, but did not test positive for SARSCoV-2 and also did not develop any COVID19 symptoms in the weeks after the test. ${ }^{22}$ One subject (24) was too ill to be tested initially. However, he reported COVID-19-associated symptoms (fever, muscle ache, fatigue, anosmia) and was tested seven weeks after his first symptoms showed. This test was negative.

Two months after the initial results were received, 14/24 test subjects (the patient-facing personnel) conducted rapid finger prick tests to assess whether they had immunity. Eleven of the 14 subjects were negative, but the two subjects who tested positive ( 9 and 12) were found to have a mild result with faint IgM and IgG markers. Subject 15 did not want to have further testing and was thus excluded from the rapid finger prick test. Additionally, subject 24 was found to have a strong positive result, indicating that he was also suffering from the disease.

Following this, three subjects (two that previously tested positive [ 9 and 12] and one that previously tested negative [1]) were tested using an antibody blood test (Abbott). As expected, the two that tested positive using the PCR test also tested positive using the antibody test, whereas the subject that tested negative using the PCR test also tested negative in the antibody test.

\section{Discussion}

To maintain health and safety at work as well as a safe environment for patients and dental team members, ${ }^{11,23,24}$ it was decided to test the dental team and close family contacts to assess who was suffering from COVID-19. Two of the test subjects that tested positive worked in the dental practice. Knowing their COVID-19 status was crucial to protect patients and for the rest of the family who needed to isolate. The two infected staff members tested positive again one month later. While the duration of the disease may continue for multiple weeks, it is considered not infectious anymore after about ten days. ${ }^{22,25,26,27}$ However, one of the two staff members still had slight chest pain and an occasional cough after one month. ${ }^{28}$ The other member recovered his sense of smell and taste after two weeks. After three weeks, his cough had disappeared and the energy levels were almost returning to normal. Six weeks later, the two healthcare workers tested negative for the presence of SARS-CoV-2. The PCR tests were followed up by finger prick tests to test for the antibody. Both infected staff members had 
positive responses, as had a third healthcare worker who could not be tested for the virus at the time, but showed strong symptoms of the disease. Although there have been many discussions about this antibody test, it does help to indicate that those who tested positive and then negative on COVID-19 RNA are considered to have developed immunity and it may be safe for them to return to work.

In a study conducted at the Newcastle upon Tyne Hospitals, 1,666 SARS-CoV-2 tests were conducted on 1,654 healthcare workers. ${ }^{29}$ Results showed that SARS-CoV-2 was detected in 240 (14\%) healthcare workers, with similar infectivity rates between non-clinical and clinical staff. The authors found that testing was beneficial as healthcare workers could selfisolate effectively and return to work efficiently after they had a negative test. Testing was also helpful in that workers with mild symptoms decided it would be better not to soldier on but rather to be tested and stop to self-isolate.

Although we had a small sample size focusing on the dental healthcare setting, our experiences strongly mirrored the results of the larger study at the Newcastle upon Tyne Hospitals as $14 \%$ also tested positive (3/24), two clinical and one non-clinical, and as early testing was essential to identify infected staff members even before symptoms were shown. This enabled effective and immediate selfisolation, which helped reduce the spread of the disease and also helped workers to efficiently return back to the office. . $30,31,32,33^{-}$

In addition, several more studies aimed to estimate the infection rate among healthcare workers and to validate the effect of prevention measures. ${ }^{34,35,36,37}$ While the dynamically changing landscape of the disease makes it difficult to generalise the infection rate, the studies still suggest that appropriate personal protective equipment (PPE) and countermeasures have a positive effect on the safety of healthcare workers. A study by Jamal et al. reported that no nosocomial transmissions of COVID-19 in dental care settings had been reported by April 2020. A reason might be that some dental practices went into complete shutdown (for example, in the UK), while others were restricting their treatment. The authors also emphasised that dentists are still considered a high-risk group and that adequate guidelines may help to prevent spreading of the disease. ${ }^{37}$ The beneficial effect of guidelines and PPE in dentistry was highlighted in a recent study by Ren et al. who modelled the infection rates in the dental office and estimated a probability of $0.008 \%$ of a dental health professional to contract and die from COVID-19, assuming appropriate protection measures are in place. ${ }^{38}$ The effectiveness of PPE and good protocols is also supported by the study of Lai et al., who evaluated the infection among healthcare workers in a tertiary hospital in Wuhan and reported that most infections occurred during the early stage of disease outbreak, particularly in non-first-line healthcare workers; that is, before the preventive measures were widely implemented. ${ }^{35}$

\section{Conclusion}

The available data on the efficiency of protective measures is encouraging, but further research is needed. Treatment and dental clinical protocols will evolve $e^{39,40}$ as we learn more about the virus and can better plan for future curves of the disease and future global pandemics. It is suggested that UK dental practices implement a regular COVID-19 testing protocol for their teams and for patient safety.

\section{Author contributions}

$L G$ conceived of the study, supervised its conduct and oversaw data collection. LG and SE drafted the manuscript. All authors conducted the analysis, formulated the implications of the results, and contributed substantially to the revision of the manuscript and approved the final manuscript as submitted.

\section{Conflict of interest}

All authors declare that they have no conflict of interest.

\section{References}

1. Peng X, Xu X, Li Y et al. Transmission routes of 2019nCoV and controls in dental practice. Int J Oral Sci 2020; 12: 9

2. NHS. Symptoms of coronavirus. 2020. Available at https://www.nhs.uk/conditions/coronavirus-covid-19/ symptoms/ (accessed August 2020).

3. NHS England and NHS Improvement. Urgent dental care guidance and standard operating procedure. 2020. Available online at https://www.england.nhs.uk/ coronavirus/primary-care/dental-practice/ (accessed August 2020).

4. NHS England and NHS Improvement. Guidance and standard operating procedure: COVID-19 virus testing in NHS laboratories. 2020. Available at https://www. rcpath.org/uploads/assets/90111431-8aca-4614b06633d07e2a3dd9/Guidance-and-SOP-COVID-19Testing-NHS-Laboratories.pdf (accessed March 2021).

5. Cook T M. Personal protective equipment during the coronavirus disease (COVID) 2019 pandemic - a narrative review. Anaesthesia 2020; 75: 920-927.

6. SDCEP. Management of Acute Dental Problems During COVID-19 Pandemic. 2020. Available at https://www. sdcep.org.uk/published-guidance/acute-dentalproblems-covid-19/ (accessed August 2020).
7. NHS England and NHS Improvement. Dental standard operating procedure: Transition to recovery. 2020. Available online at https://www.england.nhs.uk/ coronavirus/primary-care/dental-practice/ (accessed August 2020).

8. Alpha Omega and FGDP. Returning to Dental Practice: Realistic considerations, Practical solutions - An open letter to the profession, the governing bodies and our suppliers. 2020. Available at https://www.fgdp. org.uk/sites/fgdp.org.uk/files/editors/Returning\%20 to $\% 20$ Dental\%20Practice $\% 20-\% 20 \% 20$ Realistic $\% 20$ considerations $\% 2$ 2 \%20Practical\%20solutions\%20.pdf (accessed August 2020).

9. BAPD. Return to Practice: Position Paper. 2020. Available at https://www.bapd.org.uk/pdfs/3410Corona-BAPD-Policy-Document.pdf (accessed August 2020)

10. Office for Chief Dental Officer England. Position letter. London: NHS England and NHS Improvement, 2020.

11. CDC. Testing for COVID-19. 2020. Available at https:// www.cdc.gov/coronavirus/2019-ncov/symptomstesting/testing.html (accessed August 2020).

12. Murray M A, Schulz LA, Furst I W et al. Equal performance of self-collected and health care workercollected pharyngeal swabs for group a streptococcus testing by PCR. J Clin Microbiol 2015; 53: 573-578.

13. Public Health England. COVID-19: safe handling and processing for samples in laboratories. 2020. Available at https://www.gov.uk/government/publications/ wuhan-novel-coronavirus-guidance-for-clinicaldiagnostic-laboratories/wuhan-novel-coronavirushandling-and-processing-of-laboratory-specimens (accessed August 2020).

14. Wood V. Coronavirus: ' $100 \%$ accurate' antibody test approved for use in UK for first time. Independent (London) 2020 May 14.

15. Public Health England. COVID-19: guidance for health professionals. 2020. Available online at https:// www.gov.uk/government/collections/wuhan-novelcoronavirus (accessed August 2020).

16. Boseley S. UK coronavirus home testing to be made available to millions. The Guardian (London) 2020 March 25.

17. UK Government. Coronavirus (COVID-19) in the UK Testing. 2020. Available at https://coronavirus-staging. data.gov.uk/testing (accessed August 2020).

18. National Institutes of Health. NIH to launch publicprivate partnership to speed COVID-19 vaccine and treatment options. 2020. Available at https://www. unitedformedicalresearch.org/covid/nih-to-launchpublic-private-partnership-to-speed-covid-19-vaccineand-treatment-options/ (accessed August 2020).

19. University of Oxford. Oxford COVID-19 vaccine begins human trial stage. 2020. Available at https://www. ox.ac.uk/news/2020-04-23-oxford-covid-19-vaccinebegins-human-trial-stage (accessed August 2020).

20. Scottish Government. Coronavirus (COVID-19): test, trace, isolate, support strategy. 2020. Available online at https://www.gov.scot/publications/coronaviruscovid-19-test-trace-isolate-support/ (accessed August 2020).

21. Lomas N. NHS COVID-19: The UK's coronavirus contactstracing app explained. 2020. Available at https:// techcrunch.com/2020/05/05/nhs-covid-19-the-ukscoronavirus-contacts-tracing-app-explained/ (accessed August 2020)

22. Sri Santosh T, Parmar R, Anand H, Srikanth K, Saritha M. A Review of Salivary Diagnostics and Its Potential Implication in Detection of Covid-19. Cureus 2020; DOI: 10.7759/cureus.7708.

23. Schraer R. Covid: How to get a test for coronavirus 2020. Available at https://www.bbc.com/news/ health-51943612 (accessed March 2021).

24. Welsh Government. Getting tested for coronavirus (COVID-19). 2020. Available at https://gov.wales/applycoronavirus-test (accessed August 2020).

25. Zimmermann M, Nkenke E. Approaches to the management of patients in oral and maxillofacial surgery during COVID-19 pandemic. J Craniomaxillofac Surg 2020; 48: 521-526.

26. Pooladanda V, Thatikonda S, Godugu C. The current understanding and potential therapeutic options to combat COVID-19. Life Sci 2020; 254: 117765 
27. To K K, Tsang O T, Chik-Yan Yip C et al. Consistent detection of 2019 novel coronavirus in saliva. Clin Infect Dis 2020; 71: 841-843.

28. Fallahi H R, Keyhan S O, Zandian D, Kim S-G, Cheshmi B. Being a front-line dentist during the Covid-19 pandemic: a literature review. Maxillofac Plast Reconstr Surg 2020; DOI: 10.1186/ s40902-020-00256-5.

29. Hunter E, Price D A, Murphy E et al. First experience of COVID-19 screening of health-care workers in England. Lancet 2020; DOI: 10.1016/ S0140-6736(20)30970-3.

30. Kluytmans-van den Bergh M F Q, Buiting A G M, Pas S D et al. SARS-CoV-2 infection in 86 healthcare workers in two Dutch hospitals in March 2020. 2020. Available online at https://www.medrxiv.org/ content/10.1101/2020.03.23.20041913v3 (accessed August 2020).

31. Heneghan C, Oke J, Jefferson T. COVID-19 How many Healthcare workers are infected? 2020. Available at https://www.cebm.net/covid-19/covid-19-howmany-healthcare-workers-are-infected/ (accessed August 2020).

32. FNOMCeO. List of doctors who died during the Covid-19 epidemic. 2020. Available online at https:// portale.fnomceo.it/elenco-dei-medici-caduti-nelcorso-dellepidemiadi-covid-19/ (accessed May 2020).

33. Folgueira M D, Muñoz-Ruipérez, $C$, AlonsoLópez M A, Delgado R. SARS-CoV-2 infection in Health Care Workers in a large public hospital in Madrid, Spain, during March 2020. 2020. Available online at https://www.medrxiv.org/ content/10.1101/2020.04.07.20055723v2 (accessed August 2020)

34. Meng L, Hua F, Bian Z. Coronavirus Disease 2019 (COVID-19): Emerging and Future Challenges for Dental and Oral Medicine. J Dent Res 2020; 99: 481-487.

35. Lai X, Wang M, Qin C et al. Coronavirus Disease 2019 (COVID-2019) Infection Among Health Care Workers and Implications for Prevention Measures in a
Tertiary Hospital in Wuhan, China. JAMA Netw Open 2020; DOI: 10.1001/jamanetworkopen.2020.9666.

36. Kluytmans-van den Bergh M F Q, Buiting A G M, Pas $S D$ et al. Prevalence and Clinical Presentation of Health Care Workers With Symptoms of Coronavirus Disease 2019 in 2 Dutch Hospitals During an Early Phase of the Pandemic. JAMA Netw Open 2020; DOI: 10.1001/jamanetworkopen.2020.9673.

37. Jamal M, Shah M, Almarzoogi S H et al. Overview of transnational recommendations for COVID-19 transmission control in dental care settings. Oral Dis 2020; DOI: 10.1111/odi.13431.

38. Ren Y, Feng C, Rasubala L, Malmstrom H, Eliav E. Risk for dental healthcare professionals during the COVID 19 global pandemic: an evidence-based assessment. J Dent 2020; 101: 103434

39. Proffitt E. What will be the new normal for the dental industry? Br Dent J 2020; 228: 678-680.

40. Fini M B. What dentists need to know about COVID19. Oral Oncol 2020; 105: 104741 


\section{Appendix 1 Results of COVID-19 testing of dental staff and family members (HCW = healthcare worker)}

\begin{tabular}{|c|c|c|c|c|c|c|c|c|c|c|c|c|c|c|}
\hline \multirow{3}{*}{ ID } & \multirow{3}{*}{ Gender } & \multirow{3}{*}{ Age } & \multirow{3}{*}{ Profession } & \multirow{3}{*}{ Symptoms } & \multirow{3}{*}{ Medical history } & \multirow{3}{*}{ Healthcare } & \multicolumn{6}{|c|}{ COVID-19 RNA testing } & \multicolumn{2}{|c|}{ Antibody testing } \\
\hline & & & & & & & \multicolumn{2}{|c|}{ Initial test } & \multicolumn{2}{|c|}{ First follow-up } & \multicolumn{2}{|c|}{ Second follow-up } & \multirow{2}{*}{ Surescreen } & \multirow{2}{*}{ Abbott } \\
\hline & & & & & & & Date & Result & Date & Result & Date & Result & & \\
\hline 1 & F & 58 & Dentist & Sore throat & Asthma & Y & 19-Mar & Negative & - & - & - & - & N & Negative $(020620$ \\
\hline 2 & M & 60 & Dentist & - & - & Y & 19-Mar & Negative & - & - & - & - & & - \\
\hline 3 & M & 26 & Dentist & - & Asthma & Y & 19-Mar & Negative & - & - & - & - & - & - \\
\hline 4 & M & 29 & - & - & Asthma & N & 19-Mar & Negative & - & - & - & - & - & - \\
\hline 5 & M & 22 & - & - & Asthma & N & 19-Mar & Negative & - & - & - & - & - & - \\
\hline 6 & M & 17 & - & Coughing, sore throat & Asthma & N & 19-Mar & Negative & - & - & - & - & - & - \\
\hline 7 & F & 29 & - & - & - & N & 19-Mar & Negative & - & - & - & - & - & - \\
\hline 8 & M & 70 & - & Slight flu symptoms & Asthma & N & 19-Mar & Negative & - & - & - & - & - & - \\
\hline 9 & M & 26 & Dentist & - & - & Y & 19-Mar & Positive & 17-Apr & Positive & 06-May & Negative & P weak & Positive (020620) \\
\hline 10 & M & 33 & Dentist & - & - & Y & 23-Mar & Negative & - & - & - & - & N & - \\
\hline 11 & M & 38 & Dentist & - & - & Y & 23-Mar & Negative & - & - & - & - & N & - \\
\hline 12 & F & 53 & Receptionist & $\begin{array}{l}\text { Developed mild COVID-19 symptoms two days after testing } \\
\text { positive }\end{array}$ & - & Y & 23-Mar & Positive & 17-Apr & Positive & 06-May & Negative & P weak & Positive (090620) \\
\hline 13 & F & 41 & Nurse & - & Severe headache & Y & 23-Mar & Negative & 17-Apr & Negative & - & - & N & - \\
\hline 14 & F & 42 & HCW & - & Asthma & Y & 30-Mar & Negative & - & - & - & - & N & - \\
\hline 15 & $\mathrm{~F}$ & 23 & - & Fever, sore throat, coughing, anosmia & - & N & 29-Mar & Positive & - & - & - & - & - & - \\
\hline 16 & F & 49 & HCW & Fever, sore throat & - & Y & 07-Apr & Negative & - & - & - & - & N & - \\
\hline 17 & F & 33 & - & Fever, sore throat for two weeks & - & N & 07-Apr & Negative & - & - & - & - & - & - \\
\hline 18 & $\mathrm{~F}$ & 22 & Nurse & Persistent cough, fever, sore throat for three weeks & - & Y & 17-Apr & Negative & - & - & - & - & N & - \\
\hline 19 & $\mathrm{~F}$ & 54 & Receptionist & Previous sore throat & - & Y & 17-Apr & Negative & - & - & - & - & N & - \\
\hline 20 & $\mathrm{~F}$ & 41 & Nurse & Sore throat, fever, tiredness & - & Y & 17-Apr & Negative & - & - & - & - & N & - \\
\hline 21 & $\mathrm{~F}$ & 41 & Nurse & - & - & Y & 17-Apr & Negative & - & - & - & - & N & - \\
\hline 22 & $\mathrm{~F}$ & 24 & Nurse & - & - & Y & 17-Apr & Negative & - & - & - & - & $\mathrm{N}$ & - \\
\hline 23 & F & 37 & Receptionist & - & - & Y & 06-May & Negative & & & & & N & - \\
\hline 24 & M & 54 & Dentist & Muscle fatigue, anosmia, fever, aching joints, sore throat & - & Y & 06-May & Negative & - & - & - & - & Pstrong & - \\
\hline
\end{tabular}

